\title{
Julgamentos das Leis de Anistia pela Corte Interamericana de Direitos Humanos e os Esforços da Sociedade Civil na Justiça de Transição da Argentina e do Peru
}

\section{David Barbosa de Oliveira}

Doutor em Direito pela Ufpe. Professor-adjunto UFC. Professor-colaborador do Doutorado em Sociologia da Uece.dvdbarol@gmail.com

\section{Resumo}

Este artigo objetiva realizar uma análise sobre o reflexo do julgamento da Corte Interamericana de Direitos Humanos sobre o ordenamento jurídico da Argentina e do Peru, especificamente sobre suas leis de anistia. Para tanto, lançamos mão de metodologia comparativa. A fim de alcançar os objetivos aqui propostos, inicialmente buscamos explanar o método comparado, bem como os pressupostos do direito comparado quanto à matéria jurídica. Por fim, investigamos se houve algum reflexo do julgamento da Corte Interamericana de Direitos Humanos sobre as anistias desses países nos seus ordenamentos jurídicos, tendo sempre em vista as disputas e acordos sociais no estabelecimento dessas alterações. Por fim, buscamos entender se há, nessas leis de anistia, algum caráter reparador ou que fomente a persecução penal/civil de quem apoiou o regime de exceção, bem como perceber se a sociedade, o Estado e os órgãos internacionais dialogaram sobre os limites da anistia durante a reabertura política.

Palavras-chave: Direito comparado. Anistia política. Sistema Interamericano de Direitos Humanos. 


\title{
Judgments of amnesty laws by the Inter-American Court of Human Rights and civil society efforts in the Transitional Justice of Argentina and Peru
}

\begin{abstract}
This article aims to analyze the reflection of the judgment of the Inter - American Court of Human Rights on the legal order of Argentina and Peru, specifically on its amnesty laws. For this, we use comparative methodology. In order to reach the objectives proposed here initially we seek to explain the comparative method, as well as the comparative law assumptions regarding legal matters. Finally, we investigated whether there was any reflection of the judgment of the Inter-American Court of Human Rights on the amnesties of these countries in their legal systems, always having in mind the disputes and social agreements in the establishment of these alterations. Finally, we wonder if there are any of these amnesty laws that are reparatory or that promote the criminal/civil prosecution of those who supported the regime of exception, as well as to understand if society, the State and international agents discussed the limits of amnesty during the democratic reopening.
\end{abstract}

Keywords: Comparative law. Political amnesty. Inter-American System of Human Rights.

Recebido em: 24/2/2017

Revisões requeridas em: 2/12/2017

Aceito em: 22/12/2017

\section{Sumário}

Introdução. 2 Do método comparado nas Ciências Sociais ao Direito comparado. 3 Reflexos dos julgamentos da CIDH nos textos normativos e nas normas internas da Argentina e do Peru. 4 Considerações finais. 5 Referências. 


\section{INTRODUÇÃO}

A anistia é direito que interessa tanto aos nacionais que atravessam crises institucionais, como a transição de um regime autoritário a um democrático, quanto aos sistemas internacionais de proteção dos direitos humanos que podem julgar o Estado ante o descumprimento dos tratados por esse assinado. Assim, podemos afirmar que este estudo se relaciona com a Constituição, uma vez que as leis de anistia infraconstitucionais se pautam na previsibilidade material da constituição, firmando seu plano de validade e existência, sendo matéria essencial ao Estado moderno.

Igualmente é certo ressaltar que o tema anistia também lida de muito perto com as questões dos direitos humanos. Ainda que não haja normatização internacional sobre os limites e a legitimidade das leis de anistia, inúmeros julgados da Corte Interamericana de Direitos Humanos tratam do assunto, impondo critérios de legitimidade e limites formais para aceitação das leis, rechaçando as anistias que servem tão somente para proteger sob a impunidade agressores dos direitos humanos, como demonstram o Caso Barrios Altos, Gomes Lund e Almonacid Arellano.

Desse modo, fica evidente que as leis de anistia dialogam abertamente com os diplomas internacionais de proteção aos direitos humanos, e esse fato vincula os Estados, haja vista que, como signatários, submetem-se às cortes em caso de impedimento de investigação, processamento ou julgamento dos agentes do Estado que violaram as normas do tratado ou vilipendiaram os direitos dos presos sob sua responsabilidade. Assim, como afirma Douzinas (2009), os direitos humanos são um discurso e uma prática poderosos no Direito nacional.

Essas considerações nos levam a pensar que o estudo comparado da legislação nacional, em conjunto com as práticas do Sistema Interamericano, favorece a compreensão de que esses dois sistemas jurídicos (o nacional e o internacional) não se desenvolveram em instâncias apartadas. 
Pelo contrário, conforme ensina Doehring, "ambas as esferas, a nacional e a internacional, se complementaram e sofreram influências mútuas, no que diz respeito ao surgimento de direitos individuais” (2008, p. 373).

Dito isso, o presente artigo tem o objetivo de dar continuidade a estudos desenvolvidos sobre a Justiça de Transição na América do Sul. Esta justiça, segundo Kai Ambos (2009), compreende os mecanismos e processos da sociedade para enfrentar um legado autoritário de abusos do passado em grande escala, assegurando responsabilidade, justiça e reconciliação, abrangendo a justiça realizada durante a transição de regimes (ditadura para democracia, como in casu), assim como em processos de paz dentro de um conflito em curso. Na Justiça de Transição a anistia é apenas um dos instrumentos para realizar a transição entre regimes, devendo ser somada a outros que instrumentalizem reparações, investigações, políticas de memória, dentre outros.

Nosso objetivo é realizar um estudo comparado entre as leis de anistia da América Latina, bem como observar as consequências do Sistema Interamericano de Direitos Humanos, Comissão e Corte, no direito interno desses países, almejando colaborar e, às vezes, suprir determinadas lacunas que existem nesses estudos no Brasil, e nosso problema de pesquisa é analisar as leis de anistia da Argentina e do Peru, bem como os reflexos nesses países da atuação do Sistema Interamericano. A opção pelo estudo em comparado desses dois países resulta, aqui, do fato de eles terem sido os que mais avançaram rumo à justiça transicional no continente.

Nossa hipótese é que as mostras legislativas, bem como o processo sociopolítico da Argentina e do Peru, possam dar pistas de porque a Justiça de Transição, na América do Sul, é tão díspar e apresenta soluções tão diferentes (inclusive mais avançadas) se comparada ao processo transicional brasileiro. Para dar conta disso, utilizamos pesquisa documental e metodologia eminentemente bibliográfica. Em um primeiro momento 
analisamos, nos dois países, como as leis de anistia foram gestadas no parlamento, qual seu conteúdo e como essas leis foram recepcionadas pelos militares. Em um segundo momento, buscamos observar como e sociedade civil organizada recebeu essas leis e quais estratégias foram utilizadas junto ao Sistema Interamericano para anular ou revogar tais leis, bem como tentar compreender como a sociedade e o Estado se posicionaram ante as ações da Comissão e da Corte Interamericana de Direitos Humanos (CIDH).

Por fim, buscamos entender se há nessas leis de anistia algum caráter reparador ou que fomente a persecução penal/civil de quem apoiou o regime de exceção, bem como perceber se a sociedade, o Estado e os órgãos internacionais dialogaram sobre os limites da anistia durante a reabertura política. Um último ponto que buscamos compreender nessa pesquisa, é a repercussão que os julgamentos da CIDH tiveram, se é que tiveram, sobre os ordenamentos jurídicos da Argentina e do Peru.

É importante, ainda de início, aclarar que os direitos humanos aqui são vistos a partir de sua verve crítica. Assim como Rubio, também entendemos que "los derechos humanos poseen un carácter ambivalente, tienen un potencial emancipador pero éste está construido sobre un suelo o un piso estructural de desigualdades y de asimetrías que se desenvuelven entre diferentes grupos sociales" (2015, p. 186). Em outros termos, podemos afirmar que a luta pelos direitos humanos gestados pela ordem burguesa se desenvolveu e se consolidou sobre uma divisão social, econômica, política, cultural, geográfica e epistémica que impossibilitou, por dinâmicas de dominação, que a sociedade pudesse existir viabilizando condições dignas em todas as suas dimensões. Ainda com apoio em Rubio, é irrefutável a afirmação que "el sistema sobre el que se basa la organización moderna y capitalista no permite que las luchas que lo cuestionan puedan comunicar e irradiar desde sus particularidades, un horizonte de universalidad conflic- 
tivo, más diverso, más abierto y plural" (2015, p. 186). Assim, aqui utilizamos a discussão dos direitos humanos não como um ponto de saída, mas, antes, como um espaço em disputa, como um ponto a chegar.

\section{DO MÉTODO COMPARADO NAS CIÊNCIAS SOCIAIS AO DIREITO COMPARADO}

Antes de adentrarmos no estudo do Direito Comparado, importa fazermos uma breve incursão sobre o método comparado, de modo que possamos abordar, depois, mais aprofundamente, as discussões dele decorrentes. A comparação, segundo Schneider e Schmitt (1998), enquanto momento da atividade cognitiva, pode ser considerada inerente ao processo de construção e conhecimento nas Ciências Sociais. Nesse mesmo sentido, Jolivet (1969) dispõe que a finalidade da comparação é descobrir o que de essencial e, por conseguinte, constante, há no fato social, em contraposição ao que lhe é acidental e provém de particularidades de tempo e de ambiente. Para Schneider e Schmitt,

É lançando mão de um tipo de raciocínio comparativo que podemos descobrir regularidades, perceber deslocamentos e transformações, construir modelos e tipologias, identificando continuidades e descontinuidades, semelhanças e diferenças, e explicitando as determinações mais gerais que regem os fenômenos sociais (1998, p. 49).

A comparação, destarte, aparece como sendo inerente a qualquer pesquisa no campo das Ciências Sociais, esteja ela direcionada para a compreensão de um evento singular ou voltada para o estudo de uma série de casos previamente escolhidos. Especificamente, sobre o método comparativo, contudo, Koenig (1970) afirma que ele implica comparações de vários tipos de grupos ou povos a fim de desvendar as diferenças e semelhanças em seus modos de vida. A suposição metodológica aqui é que essas divergências e similitudes fornecem chaves importantes para 
o comportamento social do homem. Daí o motivo pelo qual - conforme aponta Schneider e Schmitt (1998), para Comte, Durkheim e Weber - a análise comparativa está estreitamente relacionada à própria constituição da Sociologia.

Por certo que já encontramos em Comte o método comparativo, haja vista que, para ele, as leis gerais e invariáveis poderiam ser descobertas na Sociologia por intermédio da comparação (desde que utilizada de modo ordenado e racional), no tempo e no espaço, entre diferentes épocas ou agrupamentos humanos. É em Durkheim, no entanto, que a análise comparativa ocupa um lugar central, posto que por seu intermédio ele apresenta a solução para alguns dos problemas fundamentais das Ciências Sociais, como a difícil conciliação entre a complexidade e a generalidade da pesquisa social. Para Durkheim,

não temos senão um meio de demonstrar que um fenômeno é causa de outro, e é comparar os casos em que estão simultaneamente presentes ou ausentes, procurando ver se as variações que apresentam nestas combinações de circunstâncias testemunham que um depende do outro (1998, p. XXI).

É pela comparação entre dois fatos sociais (um crucial e um vulgar) que o sociólogo pode determinar o que é fundamental, estabelecendo a causa principal a partir da qual derivam efeitos e consequências diversas e que, portanto, merece ser investigada. O método sociológico de Durkheim, para Jolivet (1969), expõe, dentre outras coisas, a ideia de que, assemelhado ao método das ciências da natureza, deve tratar os fatos sociais como coisas, para observá-los “de fora” e excluir todas as interpretações psicológicas subjetivas, procurando explicação propriamente sociológica, de tal modo que os fatos sociais se expliquem por outros fatos sociais. Para Durkheim, “o social se explica pelo social, as cone- 
xões causais fundamentais se desvendam a partir das relações sociais por elas próprias engendradas, e, muitas vezes, não perceptíveis a 'olho nu”" (1998, p. 63).

A comparação desempenha um elemento racional de controle, selecionando as condições suficientes para a realização do fato social, como aponta Fernandes (1980). Estabelecem-se, por ela, os limites para indicar se certos efeitos podem ou não ser atribuídos a determinadas causas. $\mathrm{O}$ método comparativo, então, possibilita que se delimite um campo específico do conhecimento, permitindo que a Sociologia se firme, distanciando-se das outras Ciências Sociais.

A despeito de qual fosse a razão, o certo é que se buscava - e, por vezes, hoje, ainda se busca - o padrão de civilidade europeu nessas comparações. Em Sociologia, conforme explica Pinto Ferreira (1969), as teorias lineares da evolução social (Comte, Durkheim, Levy-Bruhl, Max Weber, Freud, Pareto, etc.) abandonam o sistema ptolomaico da História em proveito do estudo comparado das culturas, em suas diferentes manifestações, e lhes assinalando ciclo vital de nascimento, apogeu e decadência. Para ele, "a teoria linear sugere uma transformação gradual, progressiva e uniforme da sociedade, indicando o melhoramento de formas menos perfeitas para mais perfeitos ajustamentos, segundo uma direção bem definida” (1969, p. 172-173).

Mais contundente ainda é a posição de Franz Boas sobre a ideia de se utilizar o método comparativo para entender as diferenças de institutos a fim de importá-los, buscando, com isso, o desenvolvimento das estruturas micro e macroeconômicas. Boas aponta censuras ao uso do método comparativo, tal como ele estava sendo aplicado, considerando a história da evolução humana de modo linear. Boas defende que, embora existam similaridades étnicas entre duas ou mais tribos, estas não são, necessariamente, oriundas das mesmas causas, que podem ser tanto internas, fundadas sobre condições psicológicas, quanto externas, baseadas no meio em 
que elas vivem. Assume ele, portanto, uma visão de evolução multilinear da História, entendendo que o mesmo fenômeno étnico pode surgir independentemente em diversas tribos por diferentes caminhos. Boas (2004) define, então, as regras que o estudo antropológico deve seguir para atingir a galgada segurança. Inicialmente, a investigação detalhada de cada tribo deve ser preliminar a todos os estudos comparativos mais amplos. Além disso, a comparação deve se restringir apenas aos fenômenos que se provem ser efeito das mesmas causas. É necessário provar, portanto, a compatibilidade do material. Deste modo, parece desarrazoada qualquer forma de importação de institutos que almeje desconsiderar a evolução legal e social inerente do local onde será aplicada.

A comparação linear, nesse sentido, busca sempre relacionar culturas, findando por escolher a "melhor", a mais "evoluída”, e essa escolha é eurocentricamente determinada. Assim, ante o supraexplicado, tivemos sempre o cuidado, nesta pesquisa, de não buscar, no uso desse método, um pretexto para reproduzir soluções coloniais ou mesmo desprovidas de análise crítica.

Estabelecidos esses pressupostos sobre os quais partimos para a realização desse estudo, passamos, agora, a nos determos mais propriamente ao Direito Comparado. Antes, contudo, importa destacar que ele não é a simples utilização da metodologia comparada, como se poderia apreender da discussão realizada até agora. O Direito Comparado, segundo Carvalho, "talvez seja um dos raros exemplos em que ocorra uma hipertrofia do método diante do objeto estudado" (2008, p. 142). Essa hipertrofia não favorece o entendimento da matéria. $\mathrm{O}$ próprio termo Direito Comparado é consagrado, especialmente, nos países latinos, nos de língua inglesa e nos países escandinavos e eslavos, segundo Dantas (2006). Apesar da confusão que o termo e o método carregam consigo, no sentido de se poder imaginar que o Direito Comparado seria um ramo 
autônomo do Direito, essa expressão é amplamente utilizada no Brasil, sendo entendida como comparação de direitos ou utilização de método comparado. Sobre essa dificuldade terminológica, Carvalho asserta que

[...] No âmbito do Direito Comparado, todos os métodos utilizados pelos estudiosos são subsídios para a comparação. Ninguém seria ingênuo ao ponto de afirmar que o Direito Comparado, ao desenvolver seu mister, utilizar-se-ia tão-somente do método comparado (2008, p. 142).

Existe no Direito, conforme Pereira (1955), a comparação vertical e a horizontal. Na primeira, o investigador recua no tempo e vai buscar dados informativos do instituto em sua origem, procurando responder como as civilizações anteriores reagiram ante a um determinado problema e qual solução lhes deram, comparando a concepção contemporânea do instituto com os lineamentos do passado, fixando-lhe a linha de evolução que permite configurá-lo no presente e prognosticar as suas tendências no futuro. $\mathrm{Na}$ outra, o estudioso estende seu olhar para o horizonte jurídico e focaliza os sistemas atualmente em vigor entre os diversos povos, e compara-os, procurando assinalar as suas aproximações e divergências, investigando a maneira como o mesmo instituto é tratado em outro organismo jurídico, de que modo o legislador de outro país positivou as normas de seu regime, ou como os tribunais as aplicaram e os cientistas as compreenderam. No primeiro caso, temos um exemplo de História do Direito, no outro, Direito Comparado. Cláudio Souto é taxativo quanto à distinção entre as duas disciplinas, pois "quaisquer que sejam os serviços que a história comparada possa prestar ao direito comparado dogmático, será um erro confundir estas duas disciplinas. Seus objetos, como seus métodos, diferem radicalmente” (1956, p. 104). É importante ressaltar, entretanto, que, conforme afirma Tavares, “é desaconselhável dissociarem-se tempo e espaço. A história comparativa constitucional caminha junto com o direito comparado, imprimindo a necessária visão dinâmica à pesquisa neste campo" (2009, p. 99).

Por fim, importa ainda ressaltar que, segundo Serrano (2006), a simples utilização de legislação estrangeira sem se preocupar em detectar semelhanças e diferenças em torno de pontos específicos, não é realizar 
Direito Comparado. Quando se empreende um estudo de Direito Comparado, sua tarefa vai muito além daquele instante refletido na norma posta, uma vez que deve analisar o quadro geral em que a norma se encontra, inclusive doutrina e jurisprudência, conforme expões Dantas (2006). A comparação, ainda, não deve se ater somente à busca por semelhanças ou diferenças, mas também às causas que as originaram; é necessário averiguar os conceitos fundamentais sobre o qual o sistema está construído. A comparação tem de analisar o Direito em sua totalidade e não apenas no aspecto legislativo, a fim de que não se chegue a resultados equivocados. O estudo da legislação alienígena constitui, assim, uma fase preparatória para a compreensão jurídica, mas com ela não se confunde.

Dessa maneira, o Direito Comparado tem por finalidade o aperfeiçoamento do conhecimento, a classificação e o agrupamento de ordenamentos, interpretação das instituições constitucionais, preparação da normatização, unificação de direitos e harmonização da norma pluralista, e não a simples comparação entre normas alienígenas. Conforme aponta Serrano, a problemática científica do Direito Comparado "poderá ser vista como o fato, situação ou fenômeno que dá início e estimula o estudo dos elementos comuns que presidem as legislações nacionais e estrangeiras, com o objetivo de facilitar o aperfeiçoamento e aproximação progressiva dos direitos nacionais” (2006, p. 47). Daí porque, em seu objeto de estudo, segundo Pereira, “deve ter presente além da legislação, a jurisprudência, conhecimento do meio social, a prática contratual, a tendência da técnica jurídica (1955, p. 57)”.

Estabelecidos esses pressupostos dogmáticos e metodológicos sobre o Direito Comparado, passamos à análise concreta da legislação de anistia na América do Sul a fim de constatar similitudes e diferenças, de modo que se estabeleçam relações esclarecedoras sobre o instituto e sobre a realidade sociocultural dos países latino-americanos. 


\section{REFLEXOS DOS JULGAMENTOS DA CIDH NOS TEXTOS NORMATIVOS E NAS NORMAS INTERNAS DA ARGENTINA E DO PERU}

Os países latino-americanos presenciaram, no contexto da guerra fria, a instauração de regimes ditatoriais militares que buscaram a contenção da chamada ameaça comunista e, sob a égide de governos autoritários, milhares de cidadãos foram vítimas de ameaça, exílio, tortura e morte pelos regimes. Com o arrefecimento da ordem bipolar, os países fizeram, pouco a pouco, a sua transição para a democracia e, neste cenário, eram necessários instrumentos legais que possibilitassem uma relativa conciliação entre o passado ditatorial e o presente democrático. A chamada justiça de transição é atualmente o instrumento mais adequado para essas situações, contudo, no momento em que a maioria das leis de anistia da América Latina foram feitas, não havia aparato doutrinário ou jurisprudencial que ajudasse na sua feitura. Assim, as leis de anistia terminaram por conceder perdão aos crimes do período, afetando sua punibilidade e beneficiando os opositores do regime, sem ter qualquer preocupação com verdade, memória ou reparação.

$\mathrm{Na}$ análise comparada das normas de anistia dos países sul-americanos, encontramos elementos similares em várias normas, assim como percebemos alguns elementos que os distinguem no modo de efetivação da pacificação social. A escolha por Argentina e Peru dá-se em razão de eles serem os casos em que houve mais avanços no continente sobre a matéria, bem como um diálogo mais profícuo entre CIDH, sociedade e Estado. Esses dois casos nos ajudam a entender a razão do "sucesso" da transição política nos dois países e é esse o objetivo deste artigo. Nessa seção, nosso escopo é observar como o ordenamento jurídico interno reagiu aos julgamentos da $\mathrm{CIDH}$ no tocante às leis de anistia. Assim, observaremos 
como os sistemas jurídicos desses países responderam à jurisprudência da Corte, observando se o sistema transnacional é coerente e consistente, ou se há contradições entre os sistemas da CIDH e dos tribunais nacionais.

$\mathrm{Na}$ Argentina, como aponta Smulovitz , "la centralidad que adquirió la cuestión de los derechos humanos y la demanda de justicia determino la emergencia de un espacio institucional en donde su accionar aparecia como necesario para reinstalar el imperio de la ley y evitar así la repetición de los horrores del pasado" (1995, p. 95). Talvez por isso em poucos casos pôde se ver com tanta clareza o impacto do Sistema Interamericano de Proteção de Direitos Humanos no ordenamento interno. A grande quantidade de denúncias recebidas da Argentina, nos anos 70, e os tipos de violações denunciadas aí, foi um dos fatores que levou a $\mathrm{CIDH}$ a realizar uma visita àquele país em 1978. Dessa visita, segundo Nino, a Comissão Interamericana publicou "un reporte que contenía una seria condena al régimen militar argentino" (2015, p. 127). Esse reporte difundiu pelo mundo as violações massivas e sistemáticas cometidas pela ditadura argentina e obrigou o governo militar a responder internacionalmente por elas.

Explica Canton (2007) que as denúncias, a visita in loco e o reporte possibilitou que, anos depois, as vítimas de violações dos direitos humanos recorressem novamente à Comissão para que esta decidisse sobre a compatibilidade das leis de anistia com a Convenção Americana. A partir de 1987, a Comissão começou a receber petições que denunciavam que as leis de anistia violavam a Convenção Americana de Direitos Humanos. A Comissão, em 1989, após evasiva resposta do governo argentino a estas denúncias, e recomendou, por meio do informe 28/92 (COMISSÃO..., 2017a), esclarecer os fatos e individualizar os responsáveis pelas violações ocorridas durante a ditadura militar. O governo de Carlos Menem, contudo, não seguiu as recomendações da Comissão. 
Em 1996, a partir de declarações públicas de oficiais das forças armadas que reconheciam as violações ocorridas durante a ditadura, a Comissão celebrou algumas audiências, que retomaram as denúncias anteriores e assim estabeleceu-se um importante espaço de diálogo entre a sociedade civil e o Estado. Em 1995, a senhora Carmen Aguiar de Lapacó e outras organizações de direitos humanos apresentaram uma petição à Comissão, segundo expõe Burt (2011), arguindo a rejeição das autoridades argentinas de sua solicitação para conhecer o que ocorreu com sua filha Alejandra Lapacó. Em 1998, a CIDH admitiu a petição e se pôs à disposição das partes para iniciar una solução amistosa (COMISSÃO..., 2017a). Como resultado desse diálogo, o governo se comprometeu a: aceitar e garantir o direito à verdade, esgotando todos os meios para alcançar o esclarecimento sobre o sucedido com as pessoas desaparecidas; todos os casos de averiguação da verdade passaram a ser de competência exclusiva de Câmaras Nacionais, gerando maior coerência nas decisões; destacar dentro do Ministério Público um corpo de fiscais ad hoc para as causas de busca da verdade e de pessoas desaparecidas (COMISSÃO..., 2017b).

Todos esses esforços ajudaram para que, quando a discussão sobre a validade da lei de anistia chegasse à Corte Suprema de Justiça, em 2005, o caso impetrado, pelo Centro de Estudios Legales y Sociales (Cels) sobre a "desaparición del matrimonio Poblete", pudessem ser revogadas as leis de anistias. A Corte entendeu que as leis de

\footnotetext{
"obediencia debida y punto final" fuesen "inaplicables a estos delitos porque no los contemplaron o, de ser aplicables, son inconstitucionales, porque si los contemplaron, violaron el derecho internacional consuetudinario vigente al tiempo de su promulgación (...) aquellas leyes [obediencia debida y punto final] son inaplicables a los delitos de lesa humanidad o son inconstitucionales si fuesen aplicables a los delitos de esa laya. En ambas hipótesis resultan inaplicables (ARGENTINA, 2017).
} 
A decisão ratificava, segundo Miguel Arenas Meza, "las decisiones de tribunales inferiores que habian declarado inconstitucionales las referidas leyes y avalaba, a su vez, la Ley 25.779 del Congreso Nacional, que anulaba dichas leyes" (2010, p. 196). A decisão afirma que com as leis de anistia o Estado sofreu limitações ante sua obrigação de garantir os direitos contidos na Convenção Americana sobre Direitos Humanos (artigo 1.1.) e no Pacto Internacional de Direitos Civis e Políticos. Ainda segundo Meza, "en esta sentencia se puso claramente de manifiesto la importante influencia de la jurisprudencia de la Corte interamericana en los fallos y decisiones de los Tribunales internos" (2010, p. 196), demonstrando o grande impacto que as práticas e textos do Sistema Interamericano tiveram sobre o ordenamento argentino.

Peru é outro caso em que houve grande repercussão do Sistema interamericano (Comissão e Corte) em seu ordenamento jurídico. Em particular, esse é relevante porque, pela primeira vez, um caso sobre a compatibilidade das leis de anistia com a Convenção Americana chega à CIDH. Para Abramovich, a visita da CIDH ao Peru em 1992, e depois em 1999, e seu relatório sobre “'democracia e direitos humanos', junto com as sentenças paradigmáticas da Corte sobre legislação antiterrorista, liberdade de expressão e tribunais militares, contribuíram para documentar e expor a gravidade das violações cometidas durante esse período” (2009, p. 24). Esta tanto levou ao conhecimento da comunidade internacional o que aconteceu no Peru quanto fortaleceu os organismos de direitos humanos locais, constantemente desacreditados por ambos os regimes. Assim, o caso argentino e o peruano têm em comum o fato de a CIDH desempenhar um papel destacado na justiça de transição desses países.

No início dos anos 90, a Comissão começou a receber denúncias sobre execuções extrajudiciais e desaparecimentos forçados. Dessa, os casos de La Cantuta y Barrios Altos (que inclusive foi citado na decisão da Corte Argentina) são emblemáticos para o Sistema Interamericano por 
seus efeitos no processo político interno peruano. O Caso Barrios Alto findou com a Corte entendendo que são inadmissíveis as disposições de anistia, as disposições de prescrição e o estabelecimento de excludentes de responsabilidade que pretendam impedir a investigação e sanção dos responsáveis pelas violações graves dos direitos humanos. Vejamos:

41. Esta Corte considera que son inadmisibles las disposiciones de amnistía, las disposiciones de prescripción y el establecimiento de excluyentes de responsabilidad que pretendan impedir la investigación y sanción de los responsables de las violaciones graves de los derechos humanos tales como la tortura, las ejecuciones sumarias, extralegales $\mathrm{o}$ arbitrarias y las desapariciones forzadas, todas ellas prohibidas por contravenir derechos inderogables reconocidos por el Derecho Internacional de los Derechos Humanos (CORTE..., 2016a).

A Corte, então, resolveu “declarar que las leyes de amnistía 26.479 y 26.492 eran incompatibles con la Convención Americana sobre Derechos Humanos y carecen de efectos jurídicos" (CORTE..., 2016a). Mesmo que a Corte se refira, em algumas partes da sentença, às leis de anistia e, em outras, às leis de autoanistia, segundo Canton, fica evidente que "la incompatibilidad con la Convención Americana existe en cualquiera de los dos casos, siempre y cuando se den los requisitos que impidan la investigación y sanción de los responsables de las violaciones graves de los derechos humanos" (2007, p. 154).

A Corte deixa claro que nem tudo o que é legal do ponto de vista interno também o é sob o prisma internacional. Assim, a Corte fulminou as leis de anistia, pois entendeu que estas careciam de qualquer efeito jurídico, atentando, a um só tempo, ao direito da vítima à justiça e à verdade. Ademais, considerou-se que essas leis são, em sua essência, incompatíveis com a Convenção Americana, pois favorecem a impunidade e a injustiça. Cançado Trindade, em seu voto, indaga saber quem ousaria sugerir que essas leis satisfazem esses requisitos; e afirma 
Não vejo como negar que leis desse tipo carecem de caráter geral, porquanto são medidas de exceção. E certamente em nada contribuem para o bem comum, senão pelo contrário: configuram-se como meros subterfúgios para encobrir violações graves de direitos humanos, impedir o conhecimento da verdade e obstaculizar o próprio acesso à justiça por parte dos vitimados. Em suma não satisfazem os requisitos de leis no âmbito do Direito Internacional dos Direitos Humanos (2002, p. 89).

Segundo Canton (2007), o governo de Fujimori não tinha nenhuma vontade política de cumprir com as recomendações da Comissão ou das decisões da Corte. O governo buscava, a todo momento, limitar a capacidade do Sistema Interamericano, tanto que, em 8 de julho de 1999, publicou-se a resolução legislativa que retirou o reconhecimento da competência contenciosa da CIDH. Ante esse fato, a Corte resolveu que "el pretendido retiro, con efectos inmediatos, por el Estado peruano, de la declaración de reconocimiento de la competencia contenciosa de la Corte Interamericana de Derechos Humanos es inadmisible" (CORTE..., 2016b). Apenas com a saída do governo Fujimori foi retomado o diálogo com o Sistema Interamericano. Conforme Canton, "tanto el Gobierno de Valentín Paniagua como el de Alejandro Toledo sostuvieron en todo momento un diálogo con la Comisión y la sociedad civil orientado a cumplir las recomendaciones" (2007, p. 167). Para Abramovich, "o pleno retorno do Peru ao SIDH em 2001 e a aceitação da responsabilidade internacional pelos crimes atrozes do regime de Fujimori compuseram uma política essencial do governo de transição” (2009, p. 24). Assim, os governos posteriores optaram por cumprir a decisão da $\mathrm{CIDH}$, dispondo que todos os fiscais que tenham intervido em processos nos quais se aplicaram leis de anistia, devem solicitar aos respectivos juízes a execução da sentença da CIDH. 
A decisão da Corte sobre o caso Barrios Altos foi confirmada em vários procedimentos legais no Peru, incluindo uma decisão do Tribunal Constitucional, que tornou possíveis os processos criminais por violações de direitos humanos. Em 22 de setembro de 2005, a CIDH decidiu "que la obligación de dar efecto general a la declaración de ineficacia de las leyes 26.479 y 26.492 ha sido cumplida por el Estado" (CORTE..., 2017b). Uma série de outras condenações foram proferidas, entre 2006 e 2008, em casos emblemáticos, incluindo o desaparecimento de autoridades públicas em Chusci e o desaparecimento do jornalista Hugo Bustíos. Em 2008, o ex-líder do Sistema de Inteligência Nacional (SIN), Julio Salazar Monroe, foi condenado por seu papel nos desaparecimentos e assassinatos, em 1992, de estudantes e de um professor da Universidade La Cantuta. Em 2009, segundo Engstrom (2011), entendendo a Suprema Corte que Alberto Fujimori tinha sido responsável pelas mortes e desaparecimentos causados por uma unidade militar que estava sob seu comando, ratificou unanimemente o veredicto contra o então presidente de uma pena de 25 anos de prisão. O julgamento de Fujimori e seu veredicto, consoante Burt (2011), foram considerados pelo direito internacional e por especialistas em direitos humanos como um processo legal impecável, um divisor de águas nos esforços contra a impunidade no Peru e no resto do mundo.

Por fim, conforme explica Burt (2011), embora o Tribunal Constitucional do Peru tenha afirmado que o direito internacional deve ser considerado pelos tribunais peruanos nos julgamentos de casos de direitos humanos, em vários casos recentes os juízes têm ignorado ou revisado estes precedentes absolvendo os acusados. Estas tendências não são incidentes isolados; ocorreram no contexto da interferência política no processo de judicialização durante o governo García, que parece ter sido concebido para travar os esforços de responsabilização no Peru. Além disso, houve repetidos esforços para aprovar leis de anistia que encerrariam os julgamentos de direitos humanos. 


\section{CONSIDERAÇÕES FINAIS}

O locus, dentro do estudo dos direitos humanos, como dissemos anteriormente, dessa pesquisa, é a Justiça de Transição. Nessa justiça, que se ocupa de mecanismos e processos para enfrentamento de legados autoritários em grande escala, a anistia é apenas um dos instrumentos para realizar a transição entre regimes, devendo ser somada a outros que instrumentalizem reparações, investigações, políticas de memória, etc. Nesse contexto, deve-se afastar a ideia de anistia absoluta ditada pela tradicional e histórica ideia de esquecimento dos fatos e priorizar as anistias condicionadas, haja vista não eximirem automaticamente de punição os atos cometidos.

Não foi isso, contudo, que vimos no estudo comparado das leis de anistia da Argentina e do Peru. Em verdade, a realidade que é imposta pela América Latina é a do uso de leis de anistia como subterfúgio para impunidade penal. As leis de anistias estudadas não tiveram nenhuma preocupação em responsabilizar os agentes do Estado que violaram a dignidade das vítimas; pelo contrário, almejaram pôr os agentes sob o manto do esquecimento, crendo que isso pacificaria a sociedade. Assim, as leis se vincularam à clássica visão do instituto, sendo a anistia o "manto do eterno esquecimento" (BARBOSA, 1896), estando afastada da ideia de justiça transicional.

Percebemos, ainda, que, a despeito de as leis publicadas no processo de redemocratização desses países terem sido anistias absolutas, a sociedade civil, organizada e não organizada, em diálogo com o Sistema Interamericano de Direitos Humanos, conseguiu tencionar os agentes políticos e o sistema jurídico de modo a disputar não somente a formação da norma jurídica, mas o próprio texto legal. Deste modo, não podemos deixar de perceber que, em ambos os casos, o processo de redemocratização foi tenso, que a disputa pelo texto legal e sua interpretação não foi pacífico e que não houve, durante esse processo, um consenso sobre o 
perdão dos agentes do Estado. As idas e vindas, nesse processo, envolveram os três poderes, mas o que foi imperioso para os avanços sociais foi a utilização, por um relevante conjunto da sociedade, da Comissão e da Corte Interamericana.

Um último ponto que temos de destacar neste estudo é a repercussão que os julgamentos da CIDH tiveram sobre os ordenamentos jurídicos da Argentina e do Peru. O uso do Sistema Interamericano fez com que os direitos humanos fossem amplamente adotados pelos agentes do Judiciário, ocupando, nesses países, um espaço do que no Brasil é adotado pelos direitos fundamentais. Percebemos que o Sistema Interamericano, junto com a sociedade civil organizada, fomentou alterações no ordenamento interno desses países. Podemos até afirmar, indo além, que foram o sustentáculo dessa alteração, tendo inclusive servido, como vimos, na fundamentação de decisões das Cortes jurídicas desses países.

Evidencia-se, por fim, com essas observações, que os direitos humanos, tal como aponta Flores, "mais que direitos 'propriamente ditos', são processos; ou seja, o resultado sempre provisório das lutas que os seres humanos colocam em prática para ter acesso aos bens necessários para a vida” (2009, p. 28). Assim, os direitos humanos não devem confundir-se com os direitos positivados no âmbito nacional ou internacional, pois uma constituição ou um tratado internacional não criam direitos humanos. Para Flores, "o problema não é de como um direito se transforma em direito humano, mas sim como um ‘direito humano' consegue se transformar em direito".

Entendemos que esse estudo findou por demostrar esse caráter procedimental e tensional dos direitos humanos. Douzinas aponta outra interessante perspectiva: o aspecto utópico dos direitos humanos. Utópico porque permite apresentar que há ainda nesses direitos algo que os deixa, como afirma Douzinas, em "um lugar desconfortável no texto da lei, nacional ou internacional” (2009, p. 373). O esvaziamento político do 
conteúdo dos direitos humanos e a hipertrofia de sua normatividade retira deles seu aspecto emancipador, tornando-o em mais um instrumento de regulação da sociedade. Assim, ainda com Douzinas, podemos perceber que "os direitos humanos representam a necessária e impossível reinvindicação de lei e de justiça” (2009, p. 383). Os direitos humanos introduzem uma tensão nos direitos positivados decorrente das lutas sociais que lhes antecedem. É o caráter utópico desses direitos, e não o normativo, que lhe possibilita fazer a crítica e resistir às ações que impedem o pleno desenvolvimento humano. Assim, com Flores, os direitos humanos são o resultado sempre provisório da luta social pela dignidade (2009, p. 31), deste modo, podemos finalizar afirmando que a anistia Argentina e do Peru foi/é a anistia possível, e estas continuam em disputa.

\section{REFERÊNCIAS}

ABRAMOVICH, V. Das violações em massa aos padrões estruturais: novos enfoques e clássicas tensões no Sistema Interamericano de Direitos Humanos. SUR, v. 6, n. 11, p. 7-39, dez. 2009.

AMBOS, K. Justicia de transición: informes de América Latina, Alemania, Italia y España. AMBOS, K.; MALARINO, E.; ELSNER, G. (Org.). Justicia de transición: informes de América Latina, Alemania, Italia y España. Montevideo: Konrad-Adenauer-Stiftung, 2009.

ARGENTINA. Ministerio da Justicia e Derechos Humanos. Ley de Pacificación Nacional $N \square$ 22.924. Disponível em: <ttp://abc.gov.ar/docentes/efemerides/ 10dediciembre/site_10diciembre/descargas/elproceso/leypacificacion.pdfs. Acesso em: 11 jul. 2016a.

. Ministerio da Justicia e Derechos Humanos. Ley 23.040. Disponível em: <http://servicios.infoleg.gob.ar/infolegInternet/anexos/2500029999/28166/norma.htm>. Acesso em: 11 jul. 2016b. 
Ministerio da Justicia e Derechos Humanos. Lei 23.492. Disponível em: <http://servicios.infoleg.gob.ar/infolegInternet/anexos/2000024999/21864/norma.htm $\geq$. Acesso em: $1^{\circ}$ fev. 2016c.

. Ministerio da Justicia e Derechos Humanos. Lei 24.952. Disponível em: <http://servicios.infoleg.gob.ar/infolegInternet/anexos/5000054999/50364/norma.htm>. Acesso em: $1^{\circ}$ fev. 2016d.

Ministerio da Justicia e Derechos Humanos. Lei 25.779. Disponível em: <http://servicios.infoleg.gob.ar/infolegInternet/anexos/8500089999/88140/norma.htm $>$. Acesso em: $1^{\circ}$ fev. 2016e.

. Presidencia de la Nación. Ministerio de Justicia y Derechos Humanos. Disponível em: <http://www.biblioteca.jus.gov.ar/fallosimon.html>. Acesso em: 31 jan. 2017.

BARBOSA, R. Anistia inversa. Caso de Teratologia Jurídica. 2. ed. Rio de Janeiro: Typ. do Jornal do Comércio, 1896.

BATTISTESSA, G. J. D.; ZURITA, M. D. Argentina y Brasil civiles y militares: tres décadas de convivencia en perspectiva comparada. Revista Cantareira, ed. 20, p. 37-51, jan./jun. 2014.

BOAS, F. Antropologia cultural. Org. Celso Castro. Rio de Janeiro: Jorge Zahar, 2004.

BURT, J.-M. Desafiando a impunidade nas cortes domésticas: processos judiciais pelas violações de direitos humanos na América Latina. In: REÁTEGUI, Félix (Org.). Justiça de transição: manual para a América Latina. Brasília: Ministério da Justiça, 2011.

TRINDADE, A. A. Voto concordante do Juiz A. A. Cançado Trindade. In: Revista do Instituto Brasileiro de Direitos Humanos, 2002.

CANÇADO TRINDADE, V. F. D. Resenha: per non dementicare - uma análise das leis de auto-anistia na evolução jurisprudencial da Corte Interamericana de Direitos Humanos. Revista do Instituto Brasileiro de Direitos Humanos, Fortaleza, vol. 8, n. 8, p. 281-292, 2008. 
CANTON, S. A. "Leyes de amnistía". Víctimass in mordaza. El impacto del Sistema Interamericano en la Justicia Transicional en Latinoamérica: los casos de Argentina, Guatemala, El Salvador y Perú. Washington, D.C.; México: Due Process of Law Foundation; Comisión de Derechos Humanos del Distrito Federal, 2007.

CARVALHO, W. Direito comparado. Método ou ciência? Revista de Informação Legislativa. Brasília: Senado Federal; Subsecretaria de Edições Técnicas, n. 180, 2008.

COMISSÃO INTERAMERICANA DE DIREITOS HUMANOS. Informe $n^{\circ}$ 28/92. Casos 10.147, 10.181, 10.240, 10.262, 10.309 y 10.311. Argentina. 2 de octubre de 1992. Disponível em: <https://www.cidh.oas.org/annualrep/92span/Argentina10.147.htm $>$. Acesso em: 31 jan. 2017a.

Informe 70/99. Caso 12.059, Carmen Aguiar de Lapacó, 4 mayo 1999. Disponível em: <https://www.cidh.oas.org/annualrep/99span/Admisible/ Argentina12.059.htm>. Acesso em: 31 jan. 2017b.

CORTE INTERAMERICANA DE DIREITOS HUMANOS. Caso Barrios Altos Vs. Perú. Fondo. Sentencia de 14 de marzo de 2001. Serie C No. 75. Parágrafo 41. Disponível em: <http://www.corteidh.or.cr/docs/casos/articulos/ Seriec_75_esp.pdf>. Acesso: 24 jun. 2016a.

. Caso Ivcher Bronstein vs. Perú. Competencia. Sentencia del 24 de septiembre de 1999, Serie C, $\mathrm{n} \square$ 54; Corte Interamericana de Derechos Humanos. Caso del Tribunal Constitucional vs. Perú, competencia. Sentencia del 24 de septiembre de 1999, Serie C, $\mathrm{n} \square$ 55. Disponível em: <http://www.corteidh. or.cr/docs/casos/articulos/Seriec_75_esp.pdf>. Acesso: 24 jun. 2016b.

Informe 21/00. Caso 12.059, Carmen Aguiar de Lapacó, 29 feb. 2000. Disponível em: <http://www.cidh.org/annualrep/99span/Soluci\%C3\%B3n\%20 Amistosa/Argentina12059.htm>. Acesso em: 31 jan. 2017a.

Resolución de la Corte Interamericana de Derechos Humanos de 22 de septiembre de 2005. Caso Barrios Altos. Cumplimiento de sentencia. Disponível em: <www.corteidh.or.cr/docs/supervisiones/barrios_22_09_05.doc>. Acesso em: 31 jan. 2017b. 
DANTAS, I. Direito Constitucional Comparado: introdução. Teoria e metodologia. 2. ed. Rio de Janeiro: Renovar, 2006.

DOEHRING, K. Teoria do Estado. Belo Horizonte: Del Rey, 2008.

DOUZINAS, C. O fim dos direitos humanos. São Leopoldo: Unisinos, 2009.

DURKHEIM, D. É. As regras do método sociológico. São Paulo: Editora Nacional, 1998.

ENGSTROM, P. A Anistia e o Sistema Interamericano de Direitos Humanos. In: PAYNE, Leigh A.; ABRÃO, Paulo; TORELLY, Marcelo D. Brasília A anistia na era da responsabilização: o Brasil em perspectiva internacional e comparada. Ministério da Justiça, Comissão de Anistia; Oxford: Oxford University, Latin American Centre, 2011.

FERNADES, F. Fundamentos empíricos da explicação sociológica. São Paulo: T. A. Queiroz, 1980.

FERREIRA, P. Sociologia. 2. ed. Recife: Companhia Editora de Pernambuco, 1969.

FLORES, Joaquín Herrera. A reinvenção dos direitos humanos. Florianópolis: Fundação Boiteux, 2009.

HUNTER, W. Continuity or Change? Civil-Military Relations in Democratic Argentina, Chile, and Peru. Political Science Quarterly, vol. 112, n. 3, p. 453475, Autumn, 1997.

JOLIVET. R. Tratado de filosofia I: introdução geral lógica - cosmologia. Rio de Janeiro: Livraria Agir Editora, 1969.

KOENIG, S. Elementos de Sociologia. 2. ed. Rio de Janeiro: Zahar Editores, 1970.

MEZA, M. A. La contribución de la jurisprudencia de la Corte Interamericana de Derechos Humanos a la eliminación de las "Leyes de Amnistía" en América Latina: un paso decisivo en la lucha contra la impunidad. In: REY TRISTÁN, Eduardo; CALVO GONZÁLEZ, Patricia. ENCUENTRO DE LATINOAMERICANISTAS ESPAÑOLES: CONGRESO INTERNACIONAL, 14., Sep. 2010, 
Santiago de Compostela, España. Universidad de Santiago de Compostela, Centro Interdisciplinario de Estudios Americanistas Gumersindo Busto; Consejo Español de Estudios Iberoamericanos, 2010. p. 2.175-2.189.

MORALES, E. N. C. Verdad, justicia y reparación en Argentina, El Salvador y Sudáfrica. Estud. Socio-Juríd., Bogotá, Colômbia, 7, Número especial, ago. 2005, p. 200-249.

NINO, C. S. Juicio al mal absoluto: ¿Hasta donde debe llegar la justicia retroactiva en casos de violaciones masivas de los derechos humanos? 1. ed. Buenos Aires: Siglo Veintiuno Editores, 2015.

PEREIRA, C. M. da S. Direito comparado e seu estudo. Revista da Faculdade de Direito de Minas Gerais, 1955.

PERRONE-MOISÉS, C. Lei de anistia face ao Direito Internacional: "Desaparecimentos" e "direito à verdade". In: PIOVESAN, F. (Coord.). Direitos humanos, globalização econômica e integração regional. São Paulo: Max Limonad, 2002. p. 285-305.

PERU. Congreso de la República. Ley nº 26.479. Disponível em: <http://www. congreso.gob.pe/ntley/Imagenes/Leyes/26479.pdf>. Acesso em: 11 jul. 2016a.

. Congreso de la República. Ley n⿳丷ㅡ 26.492. Disponível em: <http:// www.congreso.gob.pe/ntley/Imagenes/Leyes/26492.pdf>. Acesso em: 11 jul. 2016b.

RUBIO, David Sánchez. Derechos humanos, no colonialidad y otras luchas por la dignidad: una mirada parcial y situada. Campo Jurídico, vol. 3, n. 1, p. 181-213, maio 2015

SCHNEIDER, S.; SCHMITT, C. J. O uso do método comparativo nas ciências sociais. Caderno de Sociologia, Porto Alegre, v. 9, p. 49-87, 1998.

SERRANO, P. J. Como utilizar o direito comparado para elaboração de tese científica. Rio de Janeiro: Forense, 2006. 
SMULOVITZ, C. Constituición y poder judicial en la nueva democracia Argentina. La experiencia de las instituciones. In: ACUÑA, Carlos (Comp.). La nueva matriz politica Argentina. Buenos Aires: Ediciones Nueva Visión, 1995.

SOUTO, C. Da inexistência científico-conceitual do Direito comparado: conceituação do indagar comparativo mais específico da Ciência do Direito. Recife: [s.n.], 1956.

TAVARES, A. L. de L. Notas sobre as dimensões do direito constitucional comparado. Revista Brasileira de Direito Comparado. Rio de Janeiro: Instituto de Direito Comparado Luso-brasileiro, 2009. 